ARTICLE

https://doi.org/10.1038/s41467-019-10473-w

\title{
Diatomite derived hierarchical hybrid anode for high performance all-solid-state lithium metal batteries
}

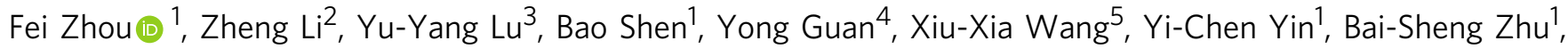

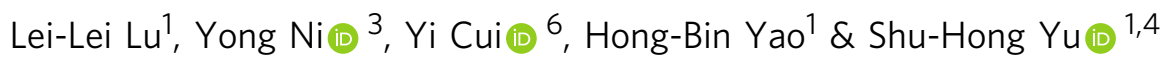

Lithium metal based anode with hierarchical structure to enable high rate capability, volume change accommodation, and dendritic suppression is highly desirable for all-solid-state lithium metal battery. However, the fabrication of hierarchical lithium metal based anode is challenging due to the volatility of lithium. Here, we report that natural diatomite can act as an excellent template for constructing hierarchical silicon-lithium based hybrid anode for high performance all-solid-state lithium metal battery. This hybrid anode exhibits stable lithium stripping/plating performance over $1000 \mathrm{~h}$ with average overpotential lower than $100 \mathrm{mV}$ without any short circuit. Moreover, all-solid-state full cell using this lithium metal composite anode to couple with lithium iron phosphate cathode shows excellent cycling stability ( $0.04 \%$ capacity decay rate for 500 cycles at $0.5 \mathrm{C})$ and high rate capability $\left(65 \mathrm{mAh} \mathrm{g}^{-1}\right.$ at 5C). The present natural diatomite derived hybrid anode could further promote the fabrication of high performance all-solid-state lithium batteries from sustainable natural resources.

\footnotetext{
${ }^{1}$ Division of Nanomaterials \& Chemistry, Hefei National Laboratory for Physical Sciences at the Microscale, CAS Center for Excellence in Nanoscience, Hefei Science Center of CAS, Department of Chemistry, University of Science and Technology of China, 230026 Hefei, Anhui, China. ${ }^{2}$ Department of Polymer Science and Engineering, University of Science and Technology of China, 230026 Hefei, Anhui, China. ${ }^{3}$ CAS Key Laboratory of Mechanical Behavior and Design of Materials, Department of Modern Mechanics, University of Science and Technology of China, 230026 Hefei, Anhui, China. ${ }^{4}$ National Synchrotron Radiation Laboratory, University of Science and Technology of China, 230026 Hefei, Anhui, China. ${ }^{5}$ Center for Micro- and Nanoscale Research and Fabrication, University of Science and Technology of China, 230026 Hefei, Anhui, China. ${ }^{6}$ Department of Materials Science and Engineering, Stanford University, Stanford, CA 94305, USA. Correspondence and requests for materials should be addressed to H.-B.Y. (email: yhb@ustc.edu.cn) or to S.-H.Y. (email: shyu@ustc.edu.cn)
} 
ithium (Li) metal anode is one of the most attractive anodes for next-generation rechargeable batteries, due to its lowest electrochemical potential $(-3.04 \mathrm{~V}$ vs. standard hydrogen electrode) and highest theoretical specific capacity $\left(3860 \mathrm{mAh} \mathrm{g}^{-1}\right)^{1-3}$. However, the application of Li metal anode in conventional liquid electrolyte-based batteries has been longterm hindered by safety issues caused by thermodynamic instability of Li metal and the flammability of organic liquid electrolyte. The heterogeneous and fragile solid electrolyte interphase (SEI) caused by the high reactivity between Li metal anode and liquid electrolyte raises up the growth of dendrite, resulting in the short circuit, thermal runaway, and eventually uncontrollable safety issues ${ }^{4-9}$. Although much effort has been made recently to reinforce as-formed SEI layer or build up an artificial SEI layer to stabilize Li metal anode to some extent, the flammable nature of liquid organic electrolyte still makes it almost unacceptable in $\mathrm{Li}$ metal-based batteries ${ }^{10,11}$

Replacement of liquid electrolytes by uninflammable solid electrolytes (SEs) to build up all-solid-state Li metal batteries is in high demand for future high-energy density and safe energystorage systems ${ }^{12-15}$. Generally, the SEs could be divided into inorganic solid electrolytes (ISEs) and solid polymer electrolytes (SPEs) ${ }^{11,12}$. Although ISEs usually exhibit high ionic conductivity at room temperature and good mechanical strength ${ }^{16-19}$, the performances of solid-state Li metal batteries based on ISEs are limited by poor rigid solid-solid contact, leading to great interfacial resistance and low interfacial compatibility between ISEs and Li metal anode 20,21 . The uneven current density distribution at the interface of Li metal and ISEs would further promote the dendrite growth along the grain boundaries of ISEs ${ }^{22,23}$. In contrast, the SPEs comprising a soft polymer matrix and a Li ion salt exhibit much better flexibility and wettability with Li metal anode than ISEs, endowing intimate interface contact and lower interfacial resistance ${ }^{24-27}$. However, the low $\mathrm{Li}$ ion conductivities of SPEs at crystalline states, in particular, polyethylene oxidebased solid polymer electrolytes (PEO-SPEs), require the operating temperature over glass-phase transition temperature ${ }^{25,28}$, with sacrificing the mechanical strength to suppress the growth of Li dendrites $22,26,29$.

Considering beyond the electrolytes, the aforementioned limitations of SEs in solid-state Li metal batteries are significantly originated from the limited active surface area and low volume accommodation capability of mostly used planar Li metal anodes. A hierarchically structured design in advanced Li metal anode to improve its rate capability, accommodate the volume change, and eliminate dendrite growth is highly demanded in solid-state $\mathrm{Li}$ metal batteries ${ }^{14,30-35}$. It can be expected that a suitable combination of hierarchically structured Li composite anode with PEOSPE could have the following advantages: the intensively enhanced electrode-electrolyte contact for low interfacial resistance and therefore improving the rate capability; the hierarchical ionic conductive framework to enable homogeneously stripping/ plating of Li and maintain the integrity of the whole electrode.

To realize the merits of a hierarchically structured $\mathrm{Li}$ composite anode with PEO-SPE, a unique hierarchical framework material has to reach the requirements of low cost, good rigidity, high affinity to $\mathrm{Li}$, and enough pore spaces $30,31,34$ to accommodate sufficient $\mathrm{Li}$ inside. Nature is a master to produce various hierarchical materials and has offered us many inspirations for advanced battery electrode designs ${ }^{36-38}$. For instance, a pomegranate-inspired nanoscale design has been used to accommodate large volume change of silicon anode and achieve high areal capacity ${ }^{36}$. After screening various hierarchically structured materials from nature, we find that the diatomite is an ideal hierarchical framework material to meet the requirements for preparing hierarchical Li composite anode. First, naturally abundant diatomite is low cost and its unique hierarchical structure with extremely high porosity is attractive for $\mathrm{Li}$ accommodation ${ }^{39-41}$. Second, with a facile magnesium reduction treatment, the unique hierarchical structure of diatomite could be totally inherited into the as-obtained silicon framework ${ }^{42}$. Third, the highly lithiophilic property of hierarchical silicon framework facilitates the lithiation process to yield a rigid $\mathrm{Li}_{4.4} \mathrm{Si}$ framework to loading $\mathrm{Li}$ metal inside, forming a unique lithium silicide-Li hybrid anode ${ }^{39,43}$.

Herein, we report a stable, dendritic free, and hierarchically structured $\mathrm{Li}$ metal-based hybrid anode derived from natural diatomite to realize high-performance all-solid-state Li metal battery. The natural diatomite is first transformed into a hierarchical silicon framework via a magnesiothermic reduction process. As shown in Fig. 1a, the diatomite-derived silicon (DF$\mathrm{Si}$ ) powder is mixed with molten Li to yield hierarchical lithium silicide-Li hybrid fragments, which could be cold-pressed into a composite anode after the PEO-SPE coating decoration. In asfabricated PEO-SPE-coated diatomite-derived lithium silicide-Li (PEO-DLSL) composite anode, Li is embedded in the hierarchical pores of the $\mathrm{Li}_{4.4} \mathrm{Si}$ framework and PEO coatings, resulting in a high electroactive contact area to homogenize the $\mathrm{Li}^{+}$ion flux and enable the anode integrity without $\mathrm{Li}$ dendrite growth (Fig. 2b). In contrast, the limited electroactive area of a planar Lifoil anode cannot efficiently avoid the growth of Li dendrites, which would easily penetrate the soft PEO-SPE causing the short circuit.

\section{Results}

Diatomite-templated fabrication of a hierarchical silicon framework for lithiation. An individual diatomite has a Petri dish morphology with a fine hierarchical pore structure, which is confirmed by both the scanning electron microscopy (SEM) and transmission electron microscopy (TEM) images (Fig. 2a, d). The bigger-sized pores $(400-800 \mathrm{~nm}$ in diameter) are distributed in the central area, whereas the smaller-sized pores $(100-200 \mathrm{~nm}$ in diameter) are uniformly distributed in the whole diatomite framework (DF). After a facile magnesiothermic reduction process, the main phase of the diatomite framework could be converted into $\mathrm{SiO}$ (denoted as DF-SiO) or $\mathrm{Si}$ (denoted as DF-Si) from initial $\mathrm{SiO}_{2}$ (JCPDS 46-1045), depending on the mass ratio of $\mathrm{Mg}$ powder to pristine diatomite. According to the powder Xray diffraction (PXRD) analysis (Supplementary Fig. 1), the $\mathrm{SiO}$ phase (JCPDS 30-1127) could be obtained if the mass ratio of $\mathrm{Mg}$ to $\mathrm{DF}$ is $0.5: 1$. When the mass ratio increased to $1: 1$, the pure phase Si (JCPDS 27-1402) could be yielded. In addition, the PXRD peaks corresponding to the crystalline phase $\mathrm{SiO}_{2}$ in diatomite (asterisk) gradually disappeared with increasing the amount of $\mathrm{Mg}$ powder. As confirmed by the SEM and TEM images (Fig. 2b, c and e, f), the generated DF-SiO and DF-Si have a similar hierarchical structure as that of pristine diatomite, especially in which the pores are maintained very well. To further reveal a good hierarchical pore structure in as-obtained frameworks, we conducted nitrogen adsorption/desorption analysis to study the variation of the specific surface area and pore structures of pristine $\mathrm{DF}, \mathrm{DF}-\mathrm{SiO}$, and $\mathrm{DF}-\mathrm{Si}$, respectively (Fig. 2g-i). The surface area of the DF-SiO and DF-Si analyzed by Brunauer-Emmett-Teller (BET) method was $199.6 \mathrm{~m}^{2} \mathrm{~g}^{-1}$ and $271.6 \mathrm{~m}^{2} \mathrm{~g}^{-1}$, respectively, higher than that of pristine DF (100.3 $\left.\mathrm{m}^{2} \mathrm{~g}^{-1}\right)$, indicating that the removing oxygen by magnesiothermic reduction process produced more void space in the framework. The three-dimensional (3D) structures of pristine DF, DF-SiO, and DF-Si were further characterized by the soft X-ray tomography (SXT) as well (Fig. 2j-1, Supplementary Movies 1-3), in which the translucent pink area is corresponding to the solid 
a

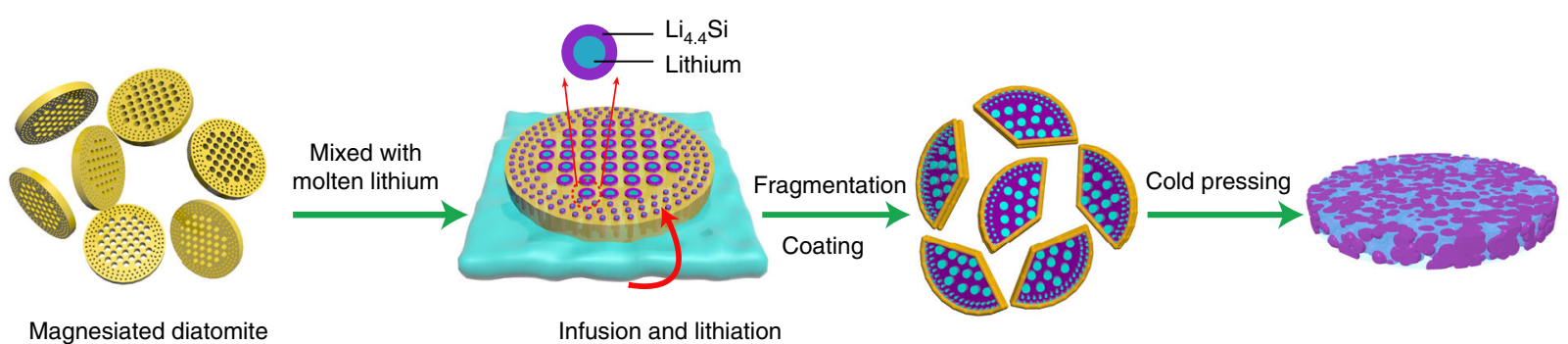

b

Magnesiated diatomite

Infusion and lithiation

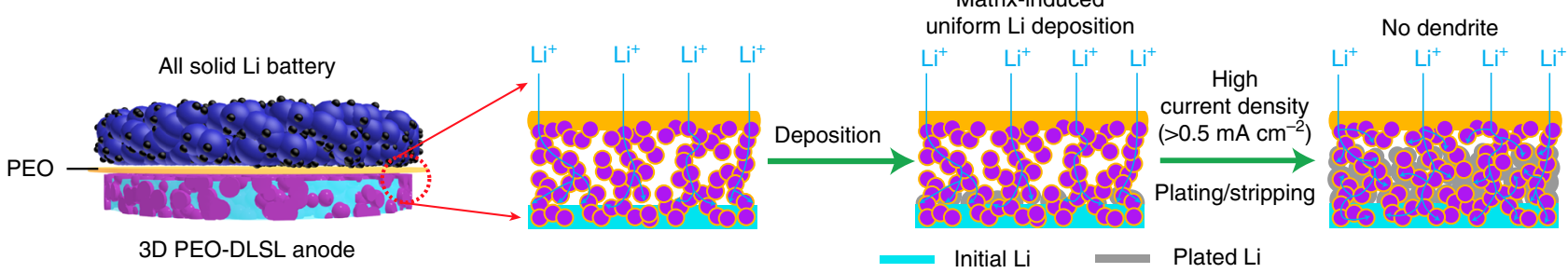

C
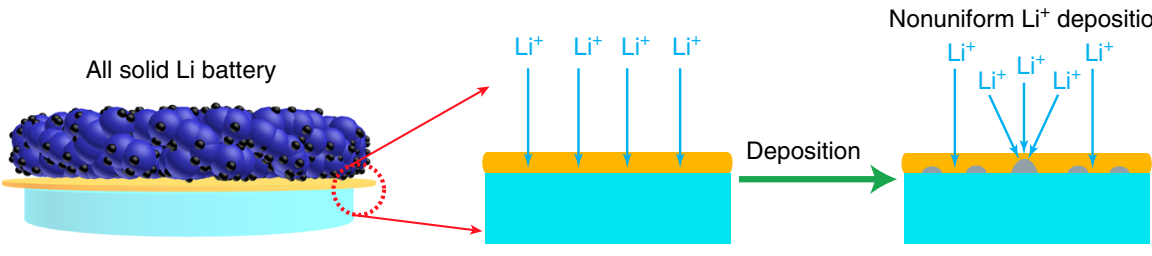

Nonuniform $\mathrm{Li}^{+}$deposition

Li foil

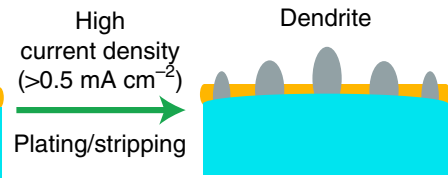

Short circuit

Fig. 1 Schematic illustration of the PEO-DLSL anode fabrication process and Li stripping/plating behaviors in comparison with a planar Li anode. a The fabrication process of PEO-DLSL. The DF-Si powder was mixed with molten Li to form the DLSL fragments and the PEO-DLSL composite anode was fabricated by cold-pressing the DLSL fragments with PEO-SPE coatings. b, $\mathbf{c}$ Li stripping/plating behavior in all-solid-state Li metal batteries with PEO-DLSL anode and a planar Li-foil anode, respectively. The effective Li+ ion flux in PEO-DLSL anode was much more uniform than that in a planar Li foil, leading to a dendrite-free anode without the short circuit

Si-based component, while the blue area could be ascribed to the hierarchical pores in the framework. It is evident that DF-Si behaves as a more porous structure with smaller sizes than that of pristine DF and DF-SiO, which will facilitate the lithiation process of as-obtained frameworks.

To evaluate the potentials of DF to fabricate a hierarchical hybrid anode via direct lithiation process, the aforementioned three products were mixed with molten $\mathrm{Li}$ with the same mass ratio of $\mathrm{M}_{\mathrm{DF} / \mathrm{DF}-\mathrm{SiO} / \mathrm{DF}-\mathrm{Si}}: \mathrm{M}_{\mathrm{Li}}=1: 1.6$ to proceed the lithiation of frameworks. Then the obtained lithiated powders were coldpressed into pallets, as the electrodes and their Li-stripping performances were tested and compared (Supplementary Fig. 2, stripped to $1.0 \mathrm{~V}$ vs. $\mathrm{Li}^{+} / \mathrm{Li}$ ). For the lithiated $\mathrm{DF}-\mathrm{Si}$ anode (DF-Si-Li), a total specific capacity of $\sim 1153 \mathrm{mAh}^{-1}$ could be extracted (based on the total electrode weight), in which the specific capacity of $\sim 838 \mathrm{mAh} \mathrm{g}^{-1}$ below the potential of $0.2 \mathrm{~V}$ is attributed from the Li metal. In contrast, the extracted specific capacity of DF-SiO-Li and DF-Li electrode was $\sim 1031 \mathrm{mAh} \mathrm{g}^{-1}$ and $\sim 924 \mathrm{mAh} \mathrm{g}^{-1}$, with only $\sim 399 \mathrm{mAh} \mathrm{g}^{-1}$ and $\sim 265 \mathrm{mAh} \mathrm{g}^{-1}$ of capacity contributed from the stripping of Li metal rather than the delithiation from $\mathrm{Li}_{4.4} \mathrm{Si}$ or $\mathrm{Li}_{2} \mathrm{O}$, respectively. This is because the DF-Si consumed a least amount of $\mathrm{Li}$ to achieve full lithiation without formation of $\mathrm{Li}_{2} \mathrm{O}$, leaving a maximum amount of $\mathrm{Li}$ to serve as $\mathrm{Li}$ metal anode. Beyond that, the lithiation product of DF-Si is pure $\mathrm{Li}_{4.4} \mathrm{Si}$ instead of the $\mathrm{Li}_{4.4} \mathrm{Si}_{-}-\mathrm{Li}_{2} \mathrm{O}$ composites formed in DF-SiO-Li and DF-Li framework, which further lowers the inner resistance of the as-formed hybrid anode. As a result, the interfacial resistance of $\mathrm{DF}-\mathrm{Si}-\mathrm{Li}$ is superior to $\mathrm{DF}-\mathrm{SiO}-\mathrm{Li}$ and DF- $\mathrm{Li}^{44,45}$. Therefore, it is evident that the full magnesiothermic reduction of diatomite into a silicon framework is required for a desirable hybrid anode framework fabrication.
Overstoichiometric lithiation of DF-Si to prepare a hybrid anode. To study the influence of the lithiation extent on DF-Si, a different amount of $\operatorname{Li}(0.2,0.5$, and $0.8 \mathrm{~g})$ was employed to react with the same mass $(0.5 \mathrm{~g})$ of DF-Si powder. The obtained products were denoted as DF-Si-Li $\mathrm{L}_{0.2}, \mathrm{DF}-\mathrm{Si}-\mathrm{Li}_{0.5}$, and DF-Si-Li $\mathrm{L}_{0.8}$, respectively. When the amount of $\mathrm{Li}$ was $0.2 \mathrm{~g}$, the fractured fragments from the DF disk (Fig. 3a) could be observed due to the strain and volume expansion induced by the lithiation (Fig. 3b). When the amount of $\mathrm{Li}$ increased to $0.5 \mathrm{~g}$, microparticles of lithiated DF were formed (Fig. 3c). By further increasing the amount of $\mathrm{Li}$ to $0.8 \mathrm{~g}$, the dense microparticles were generated, which could be ascribed to the embedding of $\mathrm{Li}$ into the hierarchical $\mathrm{Li}_{4.4} \mathrm{Si}$ particles (Fig. 3d). The photograph of the products at the different extents of lithiation (Supplementary Fig. 3) also showed the overstoichiometric lithiation process. The color of products changed from brown (similar to that of DF-Si) to black (the color of $\mathrm{Li}_{4.4} \mathrm{Si}$ ) and then to silvery gray (the mixed color of black $\mathrm{Li}_{4.4} \mathrm{Si}$ and glossy $\mathrm{Li}$ ). To further reveal the peculiarity of a hierarchical structure of DF-Si for promoting the embedment of $\mathrm{Li}$, we applied a "phase field" method ${ }^{46,47}$ (Supplementary Note 1 and Supplementary Table 1) to simulate the variation of $\mathrm{Li}$ concentration and stress evolution in the DF-Si framework during the lithiation process. As shown in Fig. 3e, the Li concentration in the DF-Si framework first increases at the edge of macropores and then spreads out to the whole framework, coinciding with the lithiation initiation from the macropore surface contacted with molten $\mathrm{Li}$ and the followed migration of the $\mathrm{Li}$ front toward the unlithiated silicon framework. This indicates that the hierarchical structure of DF-Si played a crucial role on the thoroughly gradual spreading of Li in the matrix. Also, the lithiation-induced expansion of the as-formed lithiated phase 
a

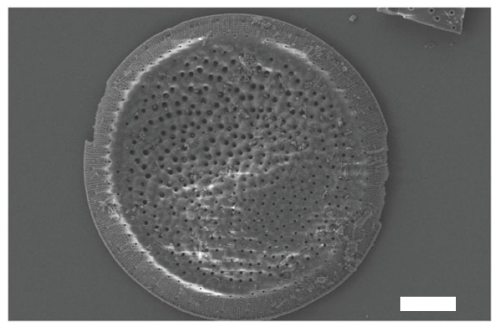

d

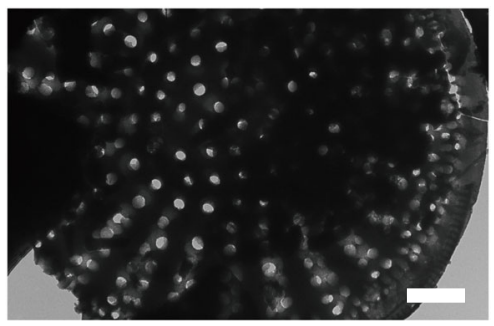

g

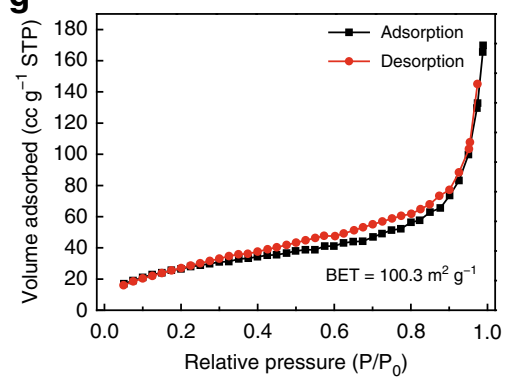

j

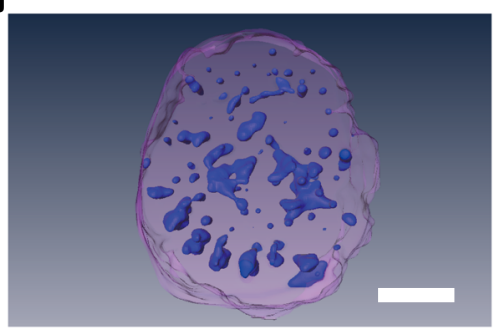

b

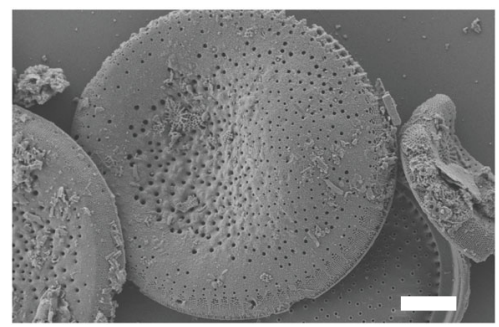

e

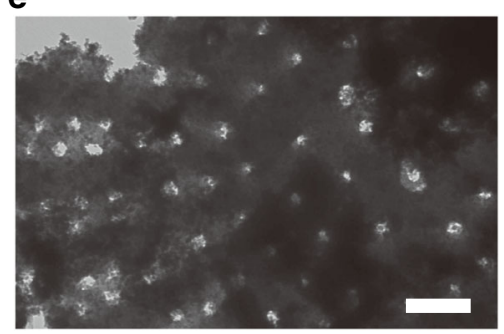

h

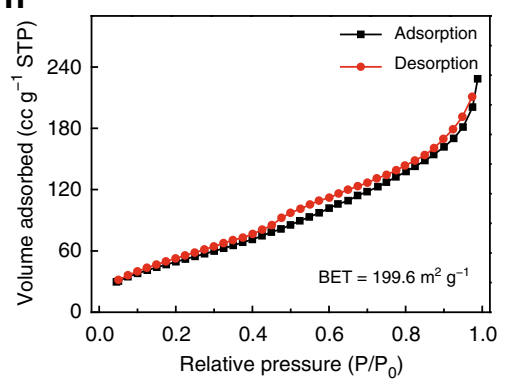

k

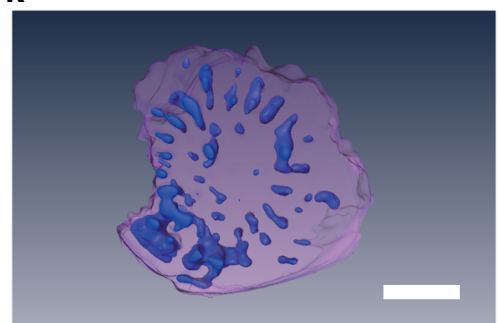

C

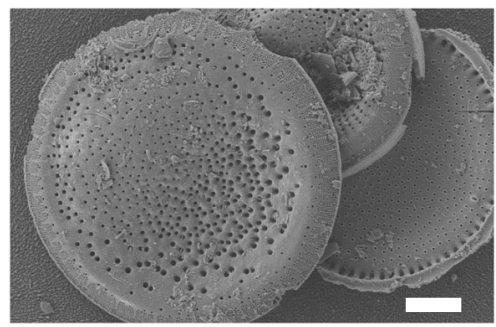

f

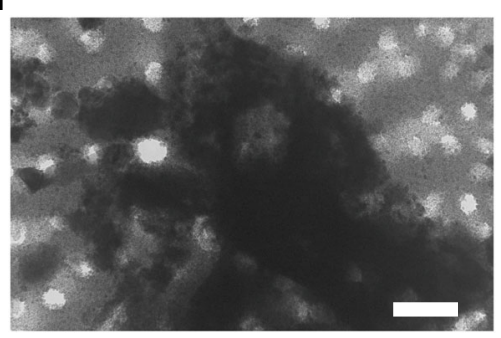

i
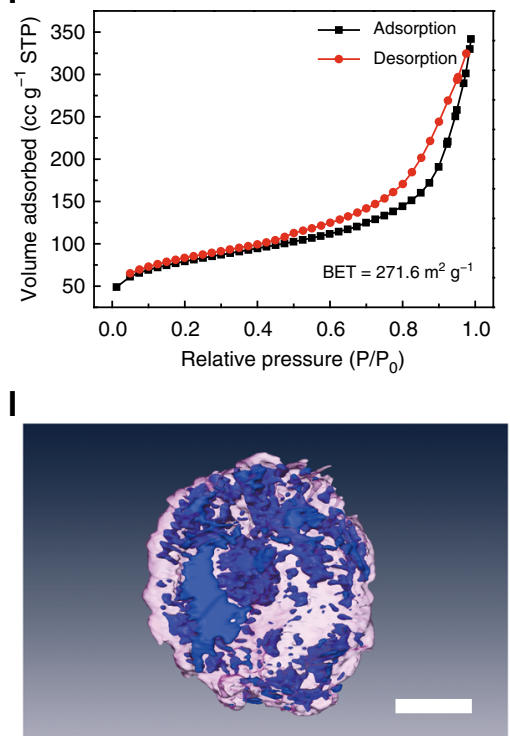

Fig. 2 Morphology and surface area characterizations of pristine DF, DF-SiO, and DF-Si, respectively. a-c SEM images of pristine DF (a scale bar $=5 \mu \mathrm{m}$ ), DF-SiO (b scale bar $=5 \mu \mathrm{m})$, and DF-Si (c scale bar $=5 \mu \mathrm{m})$, respectively. d-f TEM images of pristine DF (d scale bar $=1 \mu \mathrm{m}), \mathrm{DF}-\mathrm{SiO}(\mathbf{e} \mathrm{scale}$ bar $=500 \mathrm{~nm}$ ), and DF-Si (f scale bar $=500 \mathrm{~nm})$, respectively. $\mathbf{g}-\mathbf{i} \mathrm{N}_{2}$ adsorption/desorption curves of pristine DF (g), DF-SiO (h), and DF-Si (i), respectively. $\mathbf{j}-\mathbf{I}$ SXT images of DF (j scale bar $=2 \mu \mathrm{m})$, DF-SiO ( $\mathbf{k}$ scale bar $=2 \mu \mathrm{m})$, and DF-Si $(\mathbf{I}$ scale bar $=2 \mu \mathrm{m})$, respectively

stretches the unlithiated silicon (Supplementary Fig. 4). As a consequence, the unlithiated part suffers from tensile stress, which promotes the propagation of cracks and leads to the fragmentation of lithiated DF-Si. Comparably, the lithiation simulation of silicon microflake without hierarchical pores showed a totally different $\mathrm{Li}$ concentration and stress evolution within the lithiation process. In the dense silicon microflake, the lithiation preferred to occur at the edge of silicon microflake and only slowly spread from the edge to the center area (Supplementary Fig. 5). Due to the absence of macropores, the stress amplitude in the dense silicon microflake is lower than that in the DF-Si framework. Besides the simulation, a control lithiation experiment was conducted on silicon microparticle powder to show the superior Li uptaking capability of DF-Si. As shown in Supplementary Fig. 6, after reaction with $0.8 \mathrm{~g}$ of $\mathrm{Li}$, the silicon microparticle first became a lump of black mixture tightly adhered onto the bottom of a tantalum crucible after the lithiation, strongly contrasting to the silvery powder of as-formed
DF-Si-Li $\mathrm{L}_{0.8}$. To confirm the loading of $\mathrm{Li}$ in the hierarchical particles, the DF-Si- $\mathrm{Li}_{0.8}$ microparticles were treated by focused ion beam (FIB) etching (Supplementary Fig. 7), which showed the appearance of interconnected pores in the matrix of DF-Si-Li $\mathrm{i}_{0.8}$, indicating the embedment of $\mathrm{Li}$ in the as-formed lithium silicide framework. The SXT image of an individual DF-Si-Li ${ }_{0.8}$ microparticle (Fig. 3f, Supplementary Movie 4) was rendered according to X-ray absorption differences of $\mathrm{Li}$ and $\mathrm{Li}_{4.4} \mathrm{Si}$ (Supplementary Fig. 8). We could also observe the embedment of $\mathrm{Li}$ (red area) in the interconnected pores of the $\mathrm{Li}_{4.4} \mathrm{Si}$ framework (translucent purple area), forming the hierarchically structured hybrid anode. This hybrid anode is highly desirable to endow the good $\mathrm{Li}$ distribution in a sub-microscale hierarchical framework, leading to more uniform $\mathrm{Li}^{+}$flux and faster $\mathrm{Li}^{+}$transfer rate of solid Li metal anode.

The phase change of the lithiated DF-Si with using different amounts of $\mathrm{Li}$ was revealed by the PXRD (Fig. $3 \mathrm{~g}$ ). The main phase of DF-Si- $\mathrm{Li}_{0.2}$ could be still indexed as silicon (JCPDS 

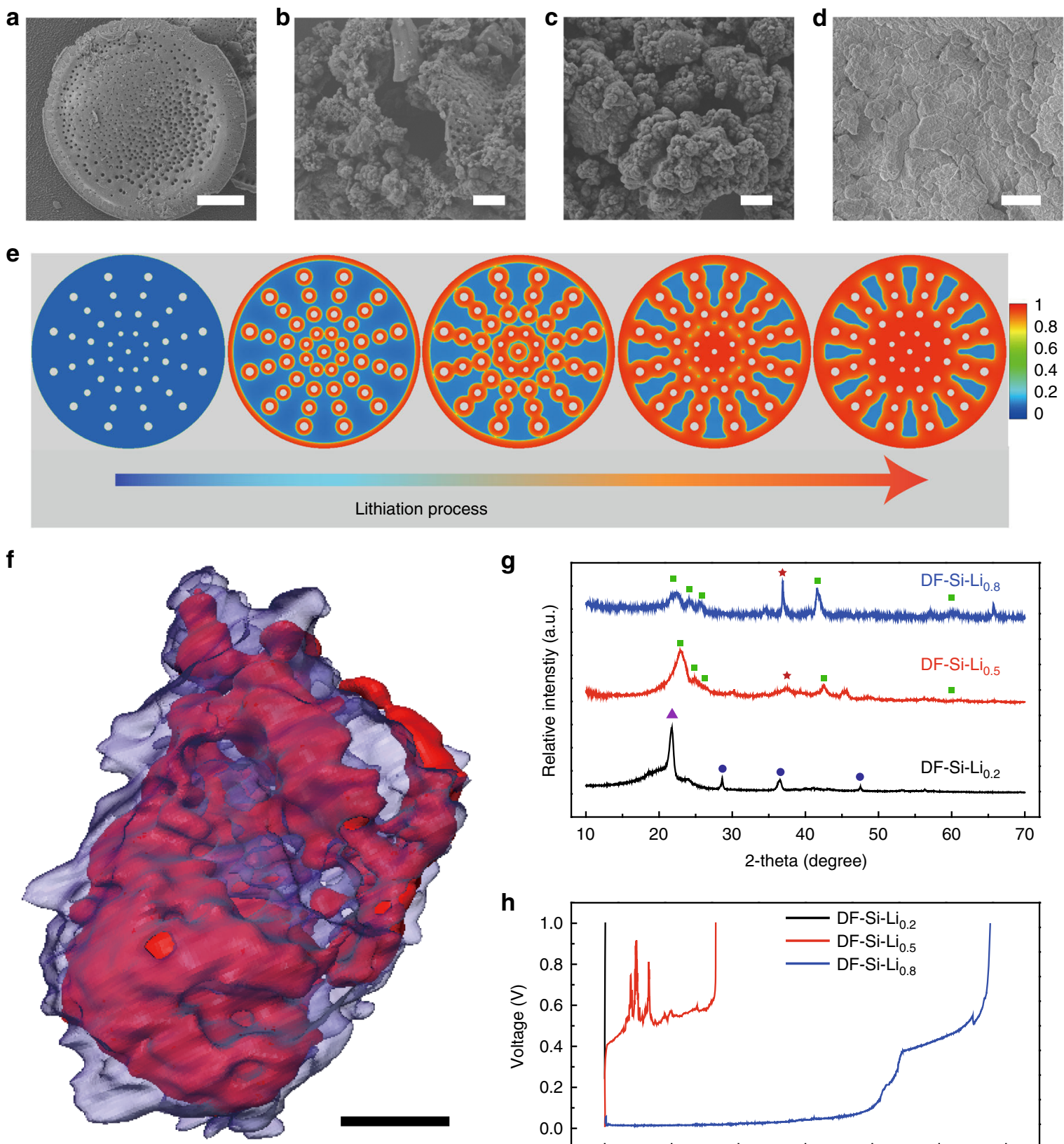

g
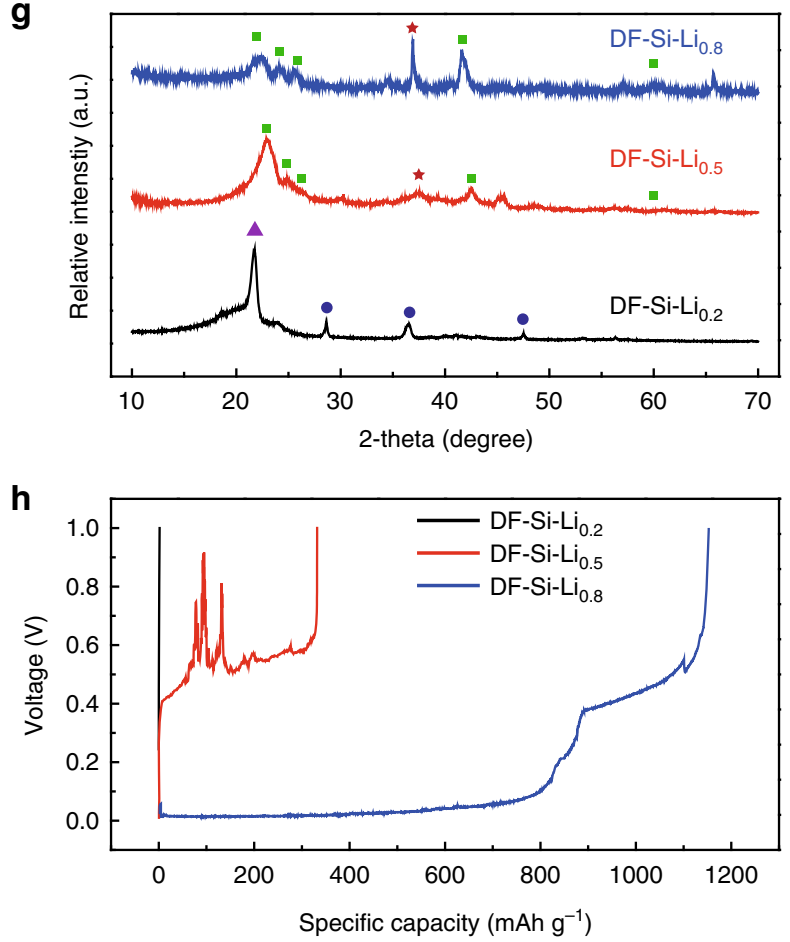

Fig. 3 Characterizations and simulations of DF-Si powder lithiated by different amounts of Li. a-d SEM images of pristine DF-Si, DF-Si-Lio.2, DF-Si-Lio.5, and DF-Si-Li ${ }_{0.8}$, respectively (scale bar $=10 \mu \mathrm{m}$ for Figure a, scale bar $=5 \mu \mathrm{m}$ for Figure $\mathbf{b}, \mathbf{c}, \mathbf{d}$ ). e The simulation of Li diffusion into the DF-Si framework during the lithiation process. The variation from the blue color to red color represents the increase of Li concentration and lithiation extent of DF-Si along with the lithiation process. $\mathbf{f} \mathrm{SXT}$ image of the DF-Si-Li ${ }_{0.8}$ microparticle (scale bar $=1 \mu \mathrm{m}$ ). The image was rendered based on the difference of $\mathrm{X}$-ray adsorption. The red color represents $\mathrm{Li}_{4.4} \mathrm{Si}$, while blue color corresponds to Li. $\mathbf{g}$ PXRD patterns of DF-Si lithiated with different amounts of Li. With a higher Li/DF-Si mass ratio, the relative intensity of the metallic peak (red asterisk) became more significant. The blue triangle denotes the peak of sample pack, the blue cycles denote the peaks of $\mathrm{Si}$, and the green squares denote the peaks of $\mathrm{Li}_{4.4} \mathrm{Si}$. $\mathbf{h}$ Li- stripping voltage plateau curves of different DF-Si-Li anodes

No. 27-1402), demonstrating that only a little amount of DF-Si was lithiated at this low amount of Li. For DF-Si- $\mathrm{Li}_{0.5}$, the main phase could be ascribed to $\mathrm{Li}_{4.4} \mathrm{Si}$ (JCPDS No. 18-0747) but the metallic Li (asterisk, JCPDS 65-9346) also existed due to the accommodation of a hierarchical framework for Li. When the mass of $\mathrm{Li}$ further increased to $0.8 \mathrm{~g}$, the relative intensity of metallic Li peaks became more significant, indicating that the overstoichiometric lithiation was conducted and the $\mathrm{Li}$ was accommodated in the matrix of $\mathrm{Li}_{4.4} \mathrm{Si}$ as confirmed by SXT
(Fig. 3f). To demonstrate the essential role of the overstoichiometric amount of $\mathrm{Li}$, we further tested the specific capacities that can be extracted from different lithiated DF-Si products. As shown in Fig. $3 \mathrm{~h}$, the DF-Si-Li ${ }_{0.8}$ anode showed a much lower charge overpotential and a higher specific capacity compared with the DF-Si- $\mathrm{Li}_{0.5}$ and DF-Si- $\mathrm{Li}_{0.2}$. In particular, the main specific capacity contribution of $\mathrm{DF}-\mathrm{Si}-\mathrm{Li}_{0.8}$ was from the metallic $\mathrm{Li}$ stripping $(838 \mathrm{mAh} / \mathrm{g}$, charge potential $<0.2 \mathrm{~V})$, while the specific capacity of $\mathrm{DF}-\mathrm{Si}-\mathrm{Li}_{0.5}$ was all from the delithiation of 

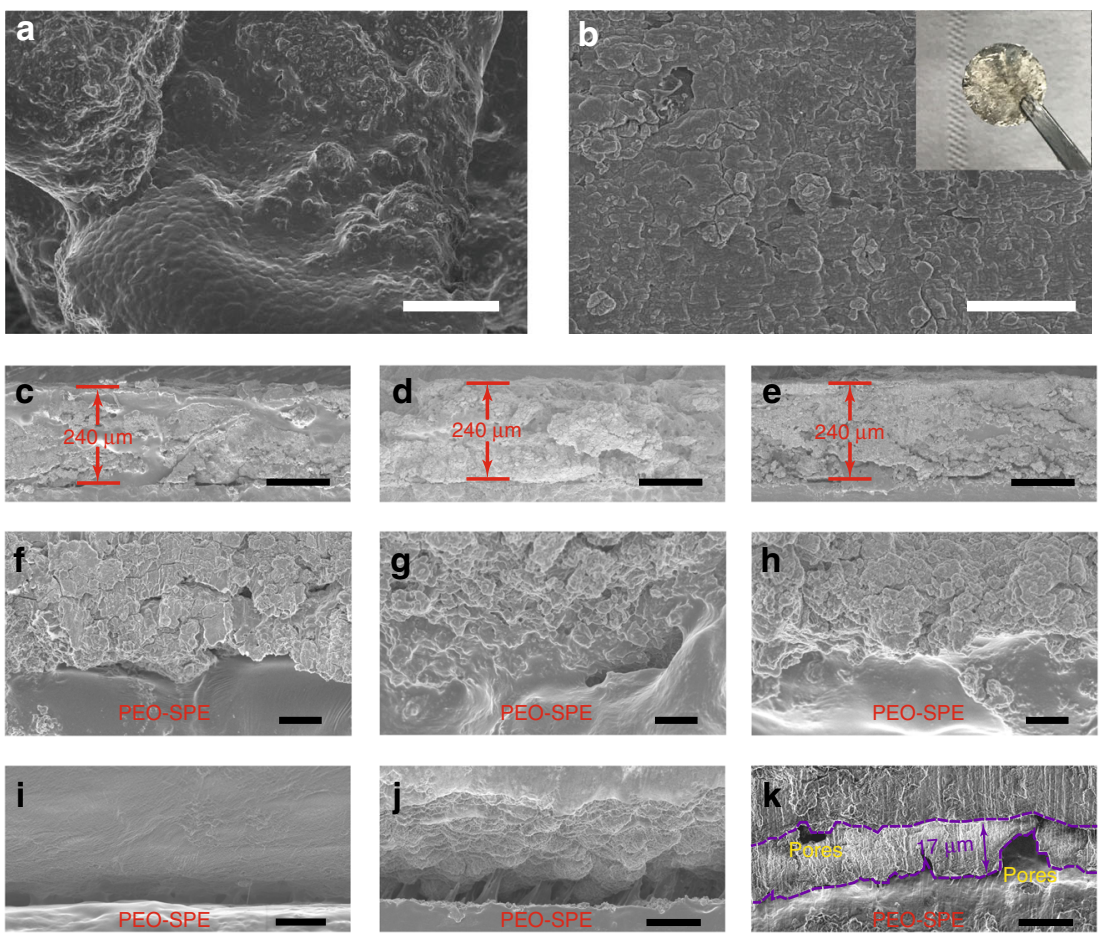

Fig. 4 Morphological and structural characterizations of PEO-DLSL and PEO-Li-foil electrode at different states. a SEM image showing the DF-Si-Li 0.8 microparticles after a thin layer of PEO-SPE coating (scale bar $=50 \mu \mathrm{m}$ ). b SEM image demonstrating the flat surface morphology of the PEO-DLSL electrode (scale bar $=20 \mu \mathrm{m}$ ). The inset is the photograph of the as-fabricated composite anode. c-e Cross-sectional SEM images of pristine PEO-DLSL electrode (c), after $4 \mathrm{mAh} \mathrm{cm}^{-2}$ of Li stripping (d), and $4 \mathrm{mAh} \mathrm{cm}^{-2}$ of plating Li back (e). The current density was set at $0.5 \mathrm{~mA} \mathrm{~cm}^{-2}$ for all of the above characterizations (scale bar $=200 \mu \mathrm{m}$ ). $\mathbf{f}-\mathbf{h}$ The corresponding magnified SEM images of the electrode from $\mathbf{c}$ to $\mathbf{e}$, showing the morphologies at the interface of the PEO-DLSL electrode and PEO-SPE (scale bar $=5 \mu \mathrm{m}$ ). $\mathbf{i}-\mathbf{k}$, Cross-sectional SEM images showing the morphologies at the interfaces of Li foil and PEO-SPE (scale bar $=20 \mu \mathrm{m}$ ). The intimal surface of Li foil is smooth (i). After $4 \mathrm{mAh} \mathrm{cm}^{-2}$ of Li stripping out, a rough Li-foil surface could be

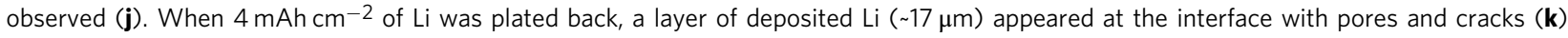

$\mathrm{Li}_{4.4} \mathrm{Si}(332 \mathrm{mAh} / \mathrm{g}$ at the potential of $0.4 \sim 1.0 \mathrm{~V})$. The charge curve of DF-Si- $\mathrm{Li}_{0.8}$ is very smooth, whereas $\mathrm{DF}-\mathrm{Si}-\mathrm{Li}_{0.5}$ is quite fluctuant due to the instability of $\mathrm{Li}_{4.4} \mathrm{Si}$ frameworks during the $\mathrm{Li}$ stripping. The DF-Si-Li $\mathrm{L}_{0.2}$ electrode showed minimal specific capacity of only $6.4 \mathrm{mAh} / \mathrm{g}$ and the voltage raised very fast over $1.0 \mathrm{~V}$. Therefore, the overstoichiometric $\mathrm{Li}$ is very crucial to achieve desired electrochemical behaviors of Li metal anode. In this case, the DF-Si- $\mathrm{Li}_{0.8}$ hybrid anode materials were used to fabricate all-solid-state Li metal composite anodes.

Fabrication and characterizations of PEO-DLSL composite anode. To fabricate the PEO-DLSL composite anode, a thin layer of PEO-SPE was first coated onto the surface of the DF-Si-Li $\mathrm{i}_{0.8}$ microparticles by a solution mixing and drying process (see the "Methods" section). As shown in Fig. 4a, the surface of DF-Si$\mathrm{Li}_{0.8}$ microparticles became smooth and no cracks could be observed, implying the uniform coating of PEO-SPE. After facile cold-pressing of as-synthesized powders, the obtained PEO-DLSL electrode shows silvery color on the surface (inset in Fig. 4b), and the SEM image of the electrode surface indicates its uniform and dense structure (Fig. 4b). The magnified cross-sectional SEM image at a stretched point (Supplementary Fig. 9a) clearly shows the silk-like structure of an elastic PEO-SPE to connect the stretched solid electrode. Furthermore, the energy-dispersive $\mathrm{X}$ ray spectroscopy (EDX) mapping results (Supplementary Fig. 9b, c) show that the oxygen signal (blue) well overlaps with the PEOSPE coating and the silicon signal (green) distributes throughout the solid electrode, implying the uniform PEO-SPE coating onto the whole $3 \mathrm{D}$ network of the $\mathrm{DF}-\mathrm{Si}-\mathrm{Li}_{0.8}$ matrix. In this composite anode, the elastic PEO-SPE could enhance the contact area between the hybrid anode and solid electrolyte. Further, PEO-SPE could construct a continuous $\mathrm{Li}^{+}$ion transport channel throughout the entire electrode, thus shortening $\mathrm{Li}^{+}$ion transportation pathway and homogenizing the $\mathrm{Li}^{+}$ion flux in the solid composite electrode. It is also worth noting that the PEO-SPE exhibits a relatively high $\mathrm{Li}^{+}$ion conductivity at the operating temperature $\left(4.63 \times 10^{-4} \mathrm{~S} \mathrm{~cm}^{-1}\right.$ at $60^{\circ} \mathrm{C}$, Supplementary Fig. 10). With the assistance of PEO-SPE, $\mathrm{Li}^{+}$ion diffusion and transportation capability in the PEO-SPE/Li-Si composite framework could be significantly improved. Therefore, the PEODLSL electrode could have a stable electrode dimensionality during the Li stripping/plating, endowed by both the rigid $3 \mathrm{D} \mathrm{Li}^{+}$ ion-conductive framework of lithiated silicon and PEO-SPE coatings. To show the sturdiness of the as-constructed $3 \mathrm{D}$ electrode network at the solid state, the PEO-DLSL electrode in a half-cell was charged to $1.0 \mathrm{~V}$ to ensure fully tripping out of all $\mathrm{Li}$. The obtained delithiated electrode still kept good rigid structural integrity, with only the color change from silvery to black, because of the formation of a porous framework, indicating the stability and interconnected nature of the PEO-DLSL framework (Supplementary Fig. 11a). In addition, hierarchical pores could be observed from the SEM image of the "black" area of the stripped electrode, where it was initially occupied by Li (Supplementary Fig. 11b).

Furthermore, the ex situ SEM characterizations were carried out to show the thickness variation of the electrode and the interfacial stability between the electrode and PEO-SPE in one cycle of the Li stripping/plating. As shown in Fig. 4c-e, the thickness of the PEO-DLSL electrode was maintained around $\sim 240 \mu \mathrm{m}$ during the stripping out and plating back $4 \mathrm{mAh} \mathrm{cm}^{-2}$ 
of $\mathrm{Li}$, indicating that the Li stripping and plating occurred inside the $3 \mathrm{D}$ framework of the composite electrode. The corresponding magnified SEM images (Fig. $4 \mathrm{f}-\mathrm{h}$ ) show the uniform electrode structure and dense interface between the electrode and PEOSPE, further confirming the homogeneous Li stripping/plating in the network of the composite electrode. In contrast, for a planar Li-foil anode, after stripping out $4 \mathrm{mAh} \mathrm{cm}^{-2}$ of $\mathrm{Li}$, the surface of Li foil at the electrode/electrolyte interface became from smooth (Fig. 4i) to uneven like hills (Fig. 4j). When $4 \mathrm{mAh} \mathrm{cm}^{-2}$ of Li was plated back, an independent layer of Li could be observed at the PEO-SPE/Li-foil interface. The average thickness of the deposited Li was about $\sim 17 \mu \mathrm{m}$, which was in consistent with the amount of plated Li (Fig. 4k). Besides, the pores and cracks appeared at both interfaces of the deposited Li layer, indicating the reduced contact area and potential growth of dendrites. It is predictive that the contact issues of $\mathrm{Li}$ foil became more severe with repeat $\mathrm{Li}$ stripping/plating process due to the extensive volume change and uneven $\mathrm{Li}$ deposition behavior.

Electrochemical performance of the PEO-DLSL anode in comparison with the $\mathrm{Li}$-foil anode. To demonstrate the good $\mathrm{Li}^{+}$ ion transfer property of the PEO-DLSL composite anode, the interfacial resistance of the symmetric cell was evaluated at first by electrochemical impedance spectroscopy (EIS). According to the EIS results in Supplementary Fig. 12, the interfacial resistance of the PEO-DLSL cell was only $124 \Omega \mathrm{cm}^{-2}$, while the value of $\mathrm{Li}$ foil cell was $397 \Omega \mathrm{cm}^{-2}$, confirming the improved interfacial $\mathrm{Li}^{+}$ transportation induced by the $3 \mathrm{D} \mathrm{Li}^{+}$ion-conductive framework in the composite anode. As shown in Fig. 5a, the PEO-DLSL symmetric cell exhibited a smaller $\mathrm{Li}$ stripping/plating overpotential compared with the Li-foil cell at $60^{\circ} \mathrm{C}$. When the current density is $0.1 \mathrm{~mA} \mathrm{~cm}^{-2}$, the average overpotential for the PEO-DLSL cell was $18 \mathrm{mV}$, lower than that of Li-foil cell $(38 \mathrm{mV}$, Fig. 5b). The difference became more significant when the cell operated at a higher current density. For example, when the current density was $0.5 \mathrm{~mA} \mathrm{~cm}^{-2}$, the average overpotential of PEO-DLSL was only $98 \mathrm{mV}$, while the value of Li foil was $276 \mathrm{mV}$ (Fig. 5c). It was observed that the voltages slowly decreased to zero when the polarizations were switched at the current density higher than $0.2 \mathrm{~mA} \mathrm{~cm}^{-2}$. This could be attributed to the concentration polarization (CP) when cycled at high current density. $\mathrm{Li}^{+}$ion transportation and diffusion rate at the electrode/electrolyte interface and in the electrolyte is order of magnitudes smaller than the electrochemical reaction rate. Therefore, the depolarization of CP required time to recover homogeneous $\mathrm{Li}^{+}$ ion concentration distribution and achieve a steady state, due to the unsatisfied $\mathrm{Li}^{+}$ion conductivity in the solid-state cell, and thus the voltages slowly decreased to zero when the polarizations were switched off. Furthermore, the $\mathrm{Li}^{+}$ion diffusion pathway in our 3D hierarchical PEO-DLSL electrode is much longer than that at the planar Li-PEO electrolyte interface. Hence, the slowly decreasing of voltage is more obvious for PEO-DLSL than Li foil. Noticeably, at the current density of $1 \mathrm{~mA} \mathrm{~cm}^{-2}$, the overpotential of PEO-DLSL was $269 \mathrm{mV}$, while the Li foil cannot be operated at $1 \mathrm{~mA} \mathrm{~cm}^{-2}$ due to the large overpotential exceeding the instrument voltage range $(5 \mathrm{~V})$. The PEO-DLSL electrode can be operated at $2 \mathrm{~mA} \mathrm{~cm}^{-2}$ as well, which exhibited stable cycling performance over $95 \mathrm{~h}$ with polarization voltage around $4 \mathrm{~V}$ (Supplementary Fig. 13). Moreover, the PEO-DLSL anode outperformed the planar Li foil in terms of cycling stability (Fig. 5d). More than $1000 \mathrm{~h}$ of stable $\mathrm{Li}$ stripping/plating with little overpotential increase can be realized at a relatively high current density and areal capacity $\left(0.5\right.$ and $\left.0.5 \mathrm{mAh} \mathrm{cm}^{-2}\right)$. In contrast, the planar Li-foil cell showed a gradual increase in voltage hysteresis over cycles, due to the accumulating interfacial impedance, followed by an internal short circuit within $100 \mathrm{~h}$. The superior rate and cycling performance of PEO-DLSL undoubtedly demonstrate the key role of a 3D hierarchical structure derived from diatomite on improving the performance of solid composite anode.

To demonstrate the feasibility of a hierarchal PEO-DLSL composite anode for all-solid-state $\mathrm{Li}$ battery, the full cells coupled with $\mathrm{LiFePO}_{4}$ (LFP) cathodes and PEO-SPE layers were assembled to test the rate capability and long-term cycling stability. Supplementary Fig. 14a shows the EIS results of full cells based on the PEO-DLSL anode and Li-foil anode. The areal resistance of LFP/PEO-DLSL was $\sim 90 \Omega \mathrm{cm}^{-2}$, much smaller than that of LFP/Li foil $\left(\sim 190 \Omega \mathrm{cm}^{-2}\right)$, indicating the lower interfacial resistance in the PEO-DLSL-based full cell. As shown in Fig. 5e, the LFP/PEO-DLSL full cell displayed a much better rate performance compared with the Li-foil-based full cell. At low current densities, the specific discharge capacity of a planar Lifoil- based cell was 148 and $144 \mathrm{mAh} \mathrm{g}^{-1}$ at 0.1 and $0.2 \mathrm{C}(1 \mathrm{C}=$ $170 \mathrm{~mA} \mathrm{~g}^{-1}$, corresponding to $0.4 \mathrm{~mA} \mathrm{~cm}^{-2}$ ), respectively, whereas the values of the PEO-DLSL-based full cell were 167 and $155 \mathrm{mAh} \mathrm{g}^{-1}$. The Li-foil-based cell exhibited a very low specific charge capacity of only $7 \mathrm{mAh} \mathrm{g}^{-1}$ at $5 \mathrm{C}$, indicating poor rate capability. In contrast, the PEO-DLSL-based cell still retained $65 \mathrm{mAh} \mathrm{g}^{-1}$ at $5 \mathrm{C}$. After decreasing the current density back to $0.2 \mathrm{C}$, the capacity of PEO-DLSL-based full cell quickly increased to $152 \mathrm{mAh} \mathrm{g}^{-1}$, disclosing a fine capacity recovery. The improved rate performance could be attributed to the fast $\mathrm{Li}^{+}$ ion transportation property at both the interface and inside the electrode induced by the PEO-SPE coating and $3 \mathrm{D} \mathrm{Li}^{+}$ionconductive $\mathrm{Li}_{4.4} \mathrm{Si}$ framework. This benefit was further confirmed by the galvanostatic discharge-charge (GDC) voltage profiles. As shown in Supplementary Fig. 14b, the LFP/PEO-DLSL and LFP/ $\mathrm{Li}$ cells both demonstrated typical $\mathrm{LiFePO}_{4}$ charge/discharge voltage plateaus at $0.2 \mathrm{C}$. However, when cycled at $2 \mathrm{C}$, the LFP/ PEO-DLSL cell exhibited a much lower charge-discharge overpotential and a higher specific capacity than that of $\mathrm{LFP} / \mathrm{Li}$ (Fig. 5f). As to the long-term cycling performance, the LFP/PEODLSL cell delivered the specific discharge capacity of $117 \mathrm{mAh} g$ ${ }^{-1}$ over 500 cycles with a very slow degradation rate $(0.04 \%$ per cycle) at $0.5 \mathrm{C}$, whereas the LFP/Li-foil full cell was short circuited at the 70th cycle (Fig. 5g). The stable composite anode integrity and intimate interface contact together helped to improve the cycling stability of the as-fabricated all-solid-state LFP/PEODLSL full cell. Among the electrochemical performance summarized in Supplementary Table 2, our developed PEO-DLSL composite anode exhibited an outstanding performance in overpotential, cycling stability, and rate capability in comparison with the previously reported Li metal anode and SPE designs for solid-state Li batteries.

\section{Discussion}

In our proposed hierarchical PEO-DLSL electrode design, the $\mathrm{Li}^{+}$ ion-conductive channels are provided by the PEO-SPE decorated $\mathrm{Li}_{4.4} \mathrm{Si}$ (PEO- $\mathrm{Li}_{4.4} \mathrm{Si}$ ) frameworks. In this context, owing to the high $\mathrm{Li}^{+}$ion conductivity of the PEO- $\mathrm{Li}_{4.4} \mathrm{Si}$ framework, our fabricated PEO-DLSL composite anode with embedded Li in a porous $\mathrm{Li}_{4.4} \mathrm{Si}$ framework and PEO-SPE coatings exhibit the following advantages. First, the porous $\mathrm{Li}_{4.4} \mathrm{Si}$ framework could act as the host to accommodate $\mathrm{Li}$ in the hierarchical pores, resulting in a robust electrode structure for electrochemical plating/stripping of $\mathrm{Li}$. Second, the $3 \mathrm{D} \mathrm{Li}_{4.4} \mathrm{Si}$ framework together with PEOSPE coatings possesses a large electrode-solid electrolyte interfacial surface area, which could reduce localized current density and suppress the dendritic growth for improving the interfacial stability. To confirm this merit, we investigated the interfacial 
a

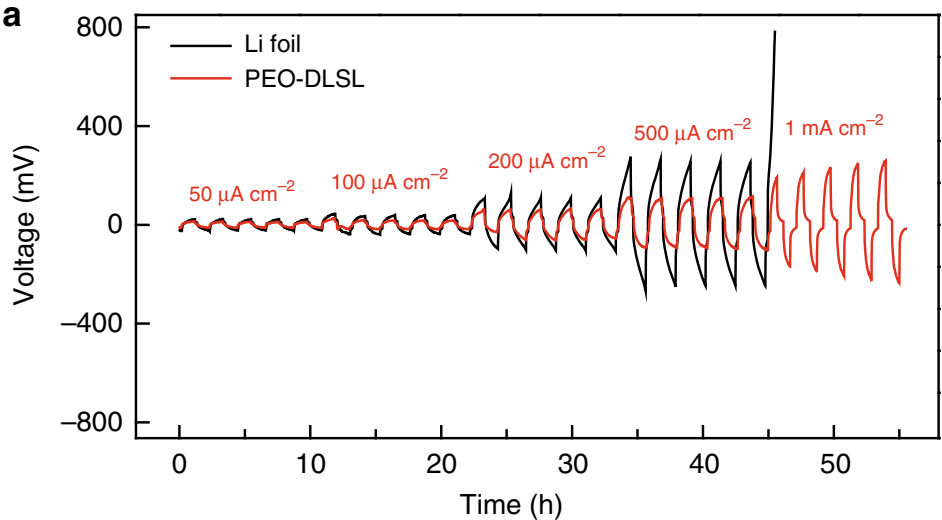

b
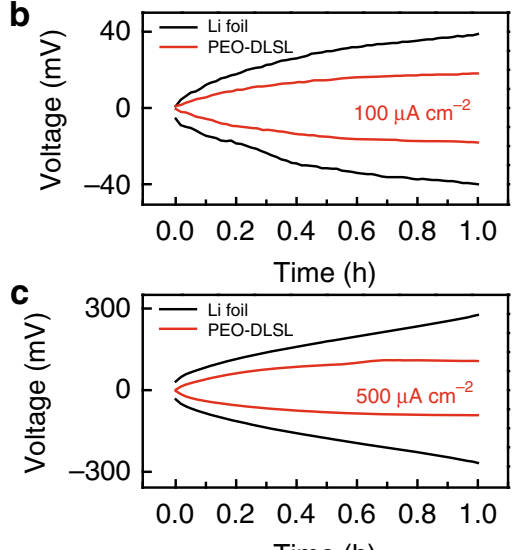

Time (h)

d

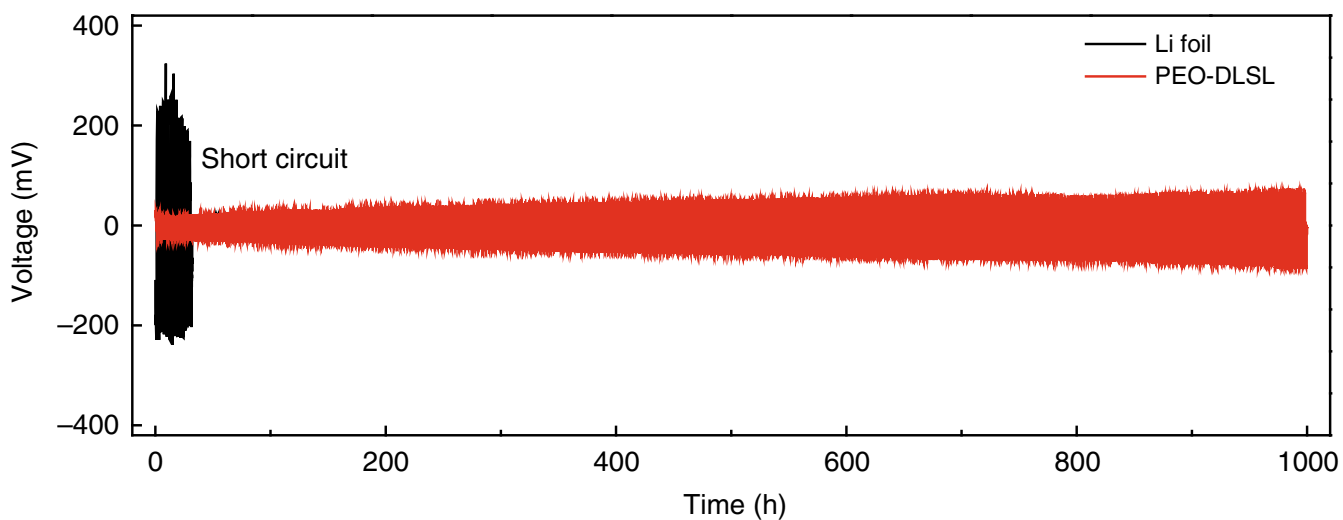

e

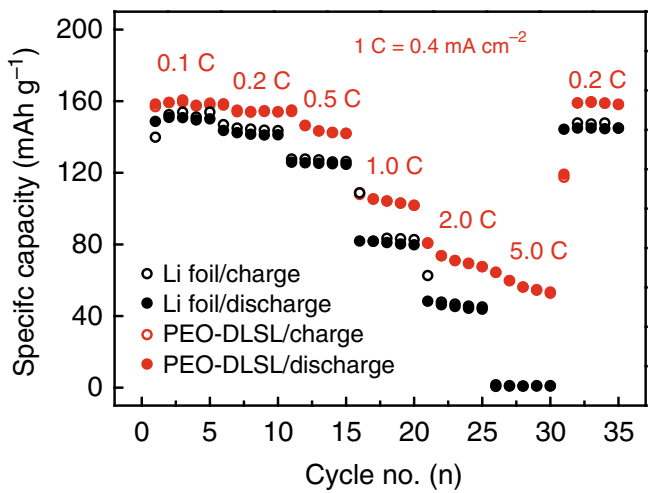

$f$

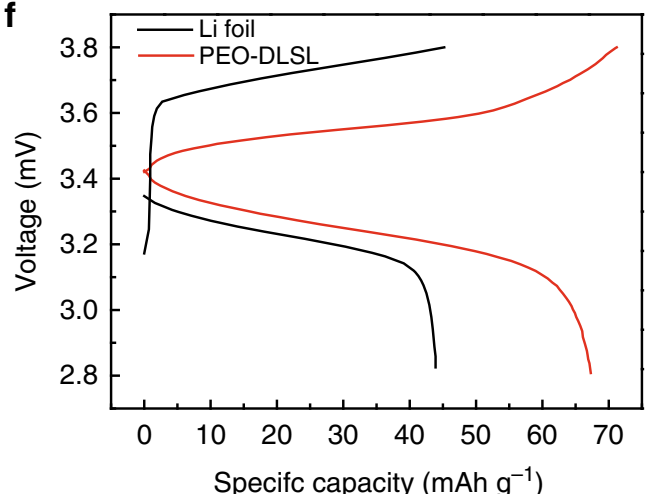

g

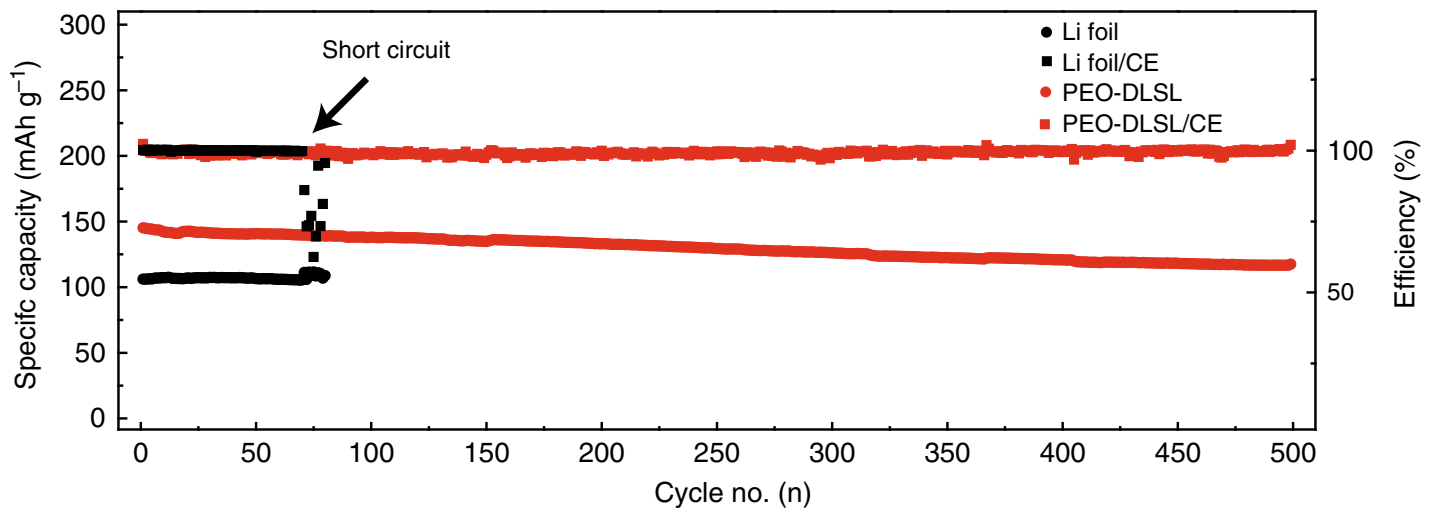

Fig. 5 Electrochemical performance comparison of the cells using PEO-DLSL and planar Li-foil anode, respectively. a Voltage profiles of symmetric cells using different anodes at different current densities. b, c Detailed voltage profiles at the current density of 0.1 and $0.5 \mathrm{~mA} \mathrm{~cm}{ }^{-2}$, respectively. d Comparison of the long-term cycling stability of the symmetric cells with PEO-DLSL and Li-foil anodes at a current density of $0.5 \mathrm{~mA} \mathrm{~cm}^{-2}$. e Rate capability comparison of Li-LFP full batteries with PEO-DLSL and Li-foil anode. $\mathbf{f}$ GDC curves of PEO-DLSL/LFP and Li-foil/LFP full cells at $2 \mathrm{C}$ current density. $\mathbf{g}$ Long-term cycling performance of batteries at a current density of $0.5 \mathrm{C}$. All cells were operated at $60^{\circ} \mathrm{C}$ 
impedance variation of symmetric and full cells using PEO-DLSL and Li-foil anodes before and after cycling, and the results are shown in Supplementary Fig. 15. In the full cells, the original areal $\mathrm{R}_{c t}$ of PEO-DLSL/LiFePO ${ }_{4}$ was $\sim 116 \Omega \mathrm{cm}^{-2}$, and it changed a little to $\sim 126 \Omega \mathrm{cm}^{-2}$ after ten cycles. Significantly, the areal $\mathrm{R}_{c t}$ of $\mathrm{Li} / \mathrm{LiFePO}_{4}$ increased obviously from $\sim 153$ to $\sim 212$ $\Omega \mathrm{cm}^{-2}$. For symmetric cells, the areal $\mathrm{R}_{c t}$ of PEO-DLSL/PEODLSL and Li/Li was $\sim 124 \Omega \mathrm{cm}^{-2}$ and $\sim 292 \Omega \mathrm{cm}^{-2}$, respectively. After 20 cycles, the corresponding areal $\mathrm{R}_{c t}$ was $\sim 138 \Omega \mathrm{cm}^{-2}$ and $\sim 307 \Omega \mathrm{cm}^{-2}$, respectively. These comparisons demonstrate that the significant role of the as-proposed 3D hierarchical design in improving the interfacial stability between the anode and the PEO-based solid electrolyte. Finally, the a 3D porous $\mathrm{Li}_{4.4} \mathrm{Si} / \mathrm{PEO}-$ SPE framework with a rigid mechanical characteristic could support the electrode with a negligible volume change during cycling, which would ensure intimate interfacial contact to further maintain the stability of the electrode.

To enable high efficiency of a hierarchical 3D electrode, the high $\mathrm{Li}^{+}$ion conductivity inside the electrode is highly desirable. In our fabricated composite anode, the $\mathrm{Li}^{+}$ionic conductivity is contributed both by the PEO-SPE decoration layer and $\mathrm{Li}_{4.4} \mathrm{Si}$ framework. It is well known that PEO-SPE is a good $\mathrm{Li}^{+}$ion conductor when working at $60^{\circ} \mathrm{C}$, showing a high $\mathrm{Li}^{+}$ionic conductivity of $4.63 \times 10^{-4} \mathrm{~S} \mathrm{~cm}^{-1}$ at $60^{\circ} \mathrm{C}$ (Supplementary Fig. 10). This means that the $\mathrm{Li}^{+}$ions can be conducted along the surface of the $\mathrm{Li}_{4.4} \mathrm{Si}$ framework in the as-fabricated hierarchical $3 \mathrm{D}$ composite anode. For the evaluation of $\mathrm{Li}^{+}$ionic conductivity in the $\mathrm{Li}_{44} \mathrm{Si}$ framework, the previously reported $\mathrm{Li}^{+}$ion diffusion coefficient of $\mathrm{Li}_{4.4} \mathrm{Si}$ was in the range from $10^{-7}$ to $10^{-13} \mathrm{~cm}^{2} \mathrm{~S}^{-1}$ at room temperature ${ }^{48-53}$, making it hard to judge the capability of the $\mathrm{Li}_{4,4} \mathrm{Si}$ framework for the $\mathrm{Li}^{+}$ionic conduction in our composite anode. In this case, we adopted the EIS comparison of the $\mathrm{Li}_{4.4} \mathrm{Si}$ electrode and PEO-SPE decorated $\mathrm{Li}_{4.4} \mathrm{Si}\left(\mathrm{PEO}-\mathrm{Li}_{4.4} \mathrm{Si}\right.$ ) electrode to reveal the $\mathrm{Li}^{+}$ionic conduction contribution of the $\mathrm{Li}_{4.4} \mathrm{Si}$ framework in our fabricated composite anode. As shown in Supplementary Fig. 16, the resistance of the $\mathrm{Li}_{4.4} \mathrm{Si}$ electrode was measured as $\sim 54 \Omega \mathrm{cm}^{-2}$, which means that the $\mathrm{Li}^{+}$ions can be conducted in the $\mathrm{Li}_{4.4} \mathrm{Si}$ framework. After making decoration of PEO on the framework, the measured resistance reduced a little to $\sim 37 \Omega \mathrm{cm}^{-2}$, indicating that the PEO decoration could enhance the $\mathrm{Li}^{+}$ion conductivity of the PEO- $\mathrm{Li}_{44} \mathrm{Si}$ electrode. On the basis of the above results, we consider that the $\mathrm{Li}^{+}$ionic conduction in the as-fabricated hierarchical 3D composite anode is endowed by both the PEO-SPE decoration layer and the $\mathrm{Li}_{4.4} \mathrm{Si}$ framework.

Beside the high $\mathrm{Li}^{+}$ion conductivity, the balance between the ionic conductivity and electronic conductivity in the solid $\mathrm{Li}$ metal anode is also needed for its interfacial stability. During the plating process, the Li would be deposited at where the sufficient $\mathrm{Li}^{+}$ions and electrons are both provided (electron/ion interface). In the traditional electrode, the electronic conductivity is much higher than $\mathrm{Li}^{+}$ion conductivity and thus the deposition of $\mathrm{Li}$ is likely to be appeared at the electrode/electrolyte interface. But in our fabricated composite electrode, the $\mathrm{Li}^{+}$ionic conductivity is dominant to make the deposition of Li occurring in the electrode framework, because of the low electronic conductivity of $\mathrm{Li}_{x} \mathrm{Si}$ $\left(3.06 \times 10^{4} \Omega \mathrm{cm}\right)^{54}$. The electron transfer is likely to be conducted in the metallic Li. As demonstrated in Supplementary Fig. 17a, plating of $\mathrm{Li}$ within the PEO- $\mathrm{Li}_{4.4} \mathrm{Si}$ framework starts from the bottom electron-conductive $\mathrm{Li}$ layer/PEO-Li $\mathrm{Li}_{4.4} \mathrm{Si}$ interface (denoted as interface I). "Fresh" Li first arises at interface I and then grows along the horizontal direction to fill the gap (Supplementary Fig. 17b). At the same time, the deposited Li could conduct electrons to the upper adjacent framework particle surface, generating a new electron $/ \mathrm{Li}^{+}$interface (interface II) and resulting in the rise of plated $\mathrm{Li}$ (Supplementary Fig. 17c). In our opinion, Li plating occurs at two orientations to fill the whole framework up ${ }^{31}$. It is noteworthy that the difference in electronic transfer ability could also explain the low charge capacity and fluctuation curve of DF-Si-Li $\mathrm{L}_{0.2}$ and DF-Si-Li $\mathrm{L}_{0.5}$ electrodes.

In summary, we report an efficient strategy to construct $3 \mathrm{D}$ hierarchical PEO-DLSL composite anode derived from natural abundant diatomite. The hierarchical structure of the PEO-DLSL composite anode inherited from natural diatomite facilitates the intimate contact between the electrode and the solid-state electrolyte, providing highly $\mathrm{Li}^{+}$ion-conductive channels, which is crucial for accommodating the interfacial fluctuation during battery cycling. As a result, low overpotential and good cycling stability could be realized in symmetric and full cells using PEODLSL composite anodes. This hierarchical Li composite anode is promising to fabricate a safe solid-state Li metal battery with high energy/power density.

\section{Methods}

Purification of diatomite. Ultrapure bio-silica microflakes (BSM) were obtained from raw diatomite after a specific purification process. Typically, the as-received diatomite powders were immersed and stirred overnight in sulfuric acid (1 M) and nitric acid ( $2 \mathrm{M})$ to remove the metal impurities and the organic constituents. The purified products were collected by filtration and washed by deionized water (DIW) and ethanol, respectively. Then the BSM with different particle sizes were separated using recycled sedimentation processes in acetone. Finally, the obtained microflakes were dried and annealed at $500{ }^{\circ} \mathrm{C}$ in air for $12 \mathrm{~h}$.

Magnesiothermic reduction of diatomite. In total, $1.0 \mathrm{~g}$ of purified diatomite was mixed with $3.0 \mathrm{~g}$ of sodium chloride (Sinopharm Chemical Reagent Co., Ltd) and a different mass of magnesium powder ( $99.5 \%$, Aladdin) by hand grinding. The mass of $\mathrm{Mg}$ was determined by the desired mass ratio $\left(\mathrm{M}_{\text {diatomite }} / \mathrm{M}_{\mathrm{Mg}}\right)$. Then the mixed powder was sealed in a tantalum crucible and transferred into a tube furnace. The crucible was then heated at $650{ }^{\circ} \mathrm{C}$ for $6 \mathrm{~h}$ in $5 \% \mathrm{H}_{2} / \mathrm{Ar}$. The magnesiated diatomite (DF-SiO or DF-Si depending on the mass ratio) was dispersed in DIW and reacted with concentrated $\mathrm{HCl}$ and $0.5 \% \mathrm{HF}$ (Sinopharm Chemical Reagent Co., Ltd) for $6 \mathrm{~h}$ by stirring. After that, the product was collected by filtration and washed with DIW and ethanol, respectively, and finally dried at $80^{\circ} \mathrm{C}$ overnight.

Overstoichiometric lithiation and PEO-SPE decoration of DF. The synthesized DF powders were first heated at $\sim 120^{\circ} \mathrm{C}$ in the argon-filled glove box for $12 \mathrm{~h}$ to remove the adsorbed $\mathrm{O}_{2} / \mathrm{H}_{2} \mathrm{O}$ before performing overstoichiometric lithiation progress. To overlithiate the DF-Si, $0.5 \mathrm{~g}$ of DF-Si powders were put into a tantalum crucible and heated on a hot plate at $\sim 350^{\circ} \mathrm{C}$. After that, Li metal (China Energy Lithium Co., Ltd) was weighted in a desired amount and put into the crucible under stirring to achieve a homogeneous reaction. Once the reaction was completed, the obtained products were cooled in the glove box to room temperature. PEO-SPE for surface decoration was synthesized by stirring a certain amount of PEO $\left(\mathrm{M}_{w}=100,000\right.$, Alfa Aesar) and lithium bis(tri-

fluoromethanesulfonyl)imide (LiTFSI, TCI Chemicals) in anhydrous acetonitrile (Energy Chemical, www.energy-chemical.com). Then the DF-Si-Li powders were mixed with PEO-SPE solution and stirred for $2 \mathrm{~h}$, and then dried at $60{ }^{\circ} \mathrm{C}$. The PEO-SPE used for the electrochemical test was fabricated by mixing a certain amount of PEO $\left(\mathrm{M}_{w}=600,000\right.$, Sigma-Aldrich $)$ and LiTFSI with gentle stirring to form a viscous solution, and then the solution was poured into a square Teflon mold $(5 \mathrm{~cm})$ and dried at $60^{\circ} \mathrm{C}$ for $24 \mathrm{~h}$. Finally, the PEO-SPE membrane was peeled off from the Teflon mold and cut into a round disk (diameter $=16 \mathrm{~mm}$ ) for the electrochemical test.

PEO-DLSL electrode fabrication. Cold-pressing method was applied to fabricate the PEO-DLSL electrode. A certain amount of DF-Li-PEO powders were weighted and put into the pellet die (diameter $=12 \mathrm{~mm}$ ) followed by $\sim 10$ tons of pressure All the steps were conducted in the glove box with $\mathrm{H}_{2} \mathrm{O}$ and $\mathrm{O}_{2}$ content below $0.1 \mathrm{ppm}$. Typically, the weight of the PEO-DLSL was about $\sim 60 \mathrm{mg}$.

Li extraction behavior of different electrodes. The Li extraction behavior of the synthesized electrodes was measured in 2032 coin cells and discharged to $1.0 \mathrm{~V}$. The composite electrodes were used as a cathode, while the Li foil was used as an anode. The electrolyte used for Li extraction is $1 \mathrm{M} \mathrm{LiPF}_{6}$ in $\operatorname{EC/DEC~}(3: 7, \mathrm{v}: \mathrm{v})$ and the current density was $10 \mu \mathrm{A} \mathrm{mg}^{-1}$.

Electrochemical performance of symmetric cells. Electrochemical performance of symmetric cells using PEO-DLSL and Li foil (diameter $=15.6 \mathrm{~mm}$, www.dodochem.com) was evaluated by 2032-coin cell batteries. The cells were assembled in an argon-filled glove box with oxygen and water content below 
$0.5 \mathrm{ppm}$. The electrolyte was PEO-SPE $\left(\mathrm{M}_{w}=600,000\right.$ for PEO with LiTFSI $)$ for solid-state cells, while $1 \mathrm{M} \mathrm{LiPF}_{6}$ in EC/DEC (www.dodochem.com) was used as liquid electrolyte. The plating/stripping performance of symmetric cells was conducted on a Land multichannel electrochemical testing system with different current density and areal capacity. Electrochemical impedence spectroscopy tests were recorded by a Bio-Logic VMP3 electrochemical working station between $1 \mathrm{M} \mathrm{Hz}$ and $1 \mathrm{~Hz}$. It is noteworthy that we set the standing time as $30 \mathrm{~min}$ for the symmetric cell cycling when the current densities were higher than $200 \mu \mathrm{A} \mathrm{cm}^{-2}$ to release possible polarization. As a result, the voltage slowly decreased to zero at the end of charge/discharge process.

\section{Electrochemical performance of all-solid-state $\mathrm{LiFePO}_{4} / \mathrm{Li}$ batteries using} different $\mathbf{L i}$ anodes. To study the electrochemical performance of $\mathrm{Li} / \mathrm{LiFePO}_{4}$ batteries, 2032 coin cells were assembled. The anode was PEO-DLSL and planar $\mathrm{Li}$ foil, respectively. For preparing the working cathode, PEO-SPE was first made by mixing PEO and LiTFSI in anhydrous acetonitrile (Energy Chemical, www.energychemical.com) and used as a binder. Then, $\mathrm{LiFePO}_{4}$ (MTI Inc.) powder, super-P acetylene black (Alfa Aesar), and PEO-SPE were mixed at a weight ratio of 80:10:10 in the N-methyl-2-pyrrolidone (NMP, Sigma-Aldrich) solvent to form a uniform slurry. Afterward, the slurry was casted on an Al-carbon foil (MTI) by a doctor blade and dried at $60{ }^{\circ} \mathrm{C}$ in vacuum. The diameter of the electrode slices was $11 \mathrm{~mm}$ with active material loading of $2.4 \mathrm{mg} \mathrm{cm}^{-2}$. The electrolyte was PEO-LiTFSI SPEs. The operating temperature was $60^{\circ} \mathrm{C}$. The rate capability test was carried out on a Land multichannel test system with different current densities between 2.3 and $3.8 \mathrm{~V}$ (vs. $\left.\mathrm{Li}^{+} / \mathrm{Li}\right)$.

Characterizations. Powder X-ray diffraction (PXRD) patterns were carried out on a Philips X'Pert PRO SUPER X-ray diffractometer equipped with graphitemonochromatized $\mathrm{Cu} \mathrm{Ka}$ radiation. Transmission electron microscope (TEM, Hitachi H-7650) and scanning electron microscope (SEM, JEOL-6700F) were employed to visualize the morphologies, sizes, structures, and elemental compositions of the products. The nitrogen absorption/desorption isotherms were obtained at $77 \mathrm{~K}$ on a Quantachrome autosorb iQ2 automated gas sorption analyzer, using BET calculations for surface area and $\mathrm{BJH}$ for pore size distribution at $77 \mathrm{~K}$. The soft X-ray beam was focused on the samples using an elliptical capillary condenser. A total of 122 projections were collected at tilt angles of -57 to $66^{\circ}$ at $1^{\circ}$ increments with 2 seconds exposures at $520 \mathrm{eV} \mathrm{X}$-ray energy. All of the projections were corrected based on a reference image with a flat field intensity and aligned to the rotation axis. Tomographic reconstruction of the projections was carried out by the total variation (TV)-based simultaneous algebraic reconstruction technique.

\section{Data availability}

The data that support the findings of this study are available from the corresponding author upon request.

Received: 20 November 2018 Accepted: 10 May 2019

Published online: 06 June 2019

\section{References}

1. Bruce, P. G., Freunberger, S. A., Hardwick, L. J. \& Tarascon, J.-M. Li-O $\mathrm{O}_{2}$ and Li-S batteries with high energy storage. Nat. Mater. 11, 19 (2011).

2. Lin, D., Liu, Y. \& Cui, Y. Reviving the lithium metal anode for high-energy batteries. Nat. Nanotech. 12, 194 (2017).

3. $\mathrm{Xu}, \mathrm{W}$. et al. Lithium metal anodes for rechargeable batteries. Energy Environ. Sci. 7, 513-537 (2014).

4. Yang, C., Fu, K., Zhang, Y., Hitz, E. \& Hu, L. Protected lithium-metal anodes in batteries: from liquid to solid. Adv. Mater. 29, 1701169 (2017).

5. Cheng, X.-B., Zhang, R., Zhao, C.-Z. \& Zhang, Q. Toward safe lithium metal anode in rechargeable batteries: a review. Chem. Rev. 117, 10403-10473 (2017).

6. Lu, Y., Tu, Z. \& Archer, L. A. Stable lithium electrodeposition in liquid and nanoporous solid electrolytes. Nat. Mater. 13, 961 (2014)

7. Zheng, G. et al. Interconnected hollow carbon nanospheres for stable lithium metal anodes. Nat. Nanotech. 9, 618 (2014).

8. Bhattacharyya, R. et al. In situ NMR observation of the formation of metallic lithium microstructures in lithium batteries. Nat. Mater. 9, 504 (2010).

9. Zhao, J. et al. Air-stable and freestanding lithium alloy/graphene foil as an alternative to lithium metal anodes. Nat. Nanotech. 12, 993 (2017).

10. Gao, Z. et al. Promises, challenges, and recent progress of inorganic solid-state electrolytes for all-solid-state lithium batteries. Adv. Mater. 30, 1705702 (2018).

11. Sun, C., Liu, J., Gong, Y., Wilkinson, D. P. \& Zhang, J. Recent advances in allsolid-state rechargeable lithium batteries. Nano Energy 33, 363-386 (2017).
12. Varzi, A., Raccichini, R., Passerini, S. \& Scrosati, B. Challenges and prospects of the role of solid electrolytes in the revitalization of lithium metal batteries. J. Mater. Chem. A 4, 17251-17259 (2016).

13. Motavalli, J. Technology: a solid future. Nature 526, S96 (2015).

14. Monroe, C. \& Newman, J. The impact of elastic deformation on deposition kinetics at lithium/polymer interfaces. J. Electrochem. Soc. 152, A396-A404 (2005).

15. Duan, H. et al. Dendrite-free li-metal battery enabled by a thin asymmetric solid electrolyte with engineered layers. J. Am. Chem. Soc. 140, 82-85 (2018).

16. Murugan, R., Thangadurai, V. \& Weppner, W. Fast lithium ion conduction in garnet-type $\mathrm{Li}_{7} \mathrm{La}_{3} \mathrm{Zr}_{2} \mathrm{O}_{12}$. Angew. Chem. Int. Ed. 46, 7778-7781 (2007).

17. Herbert, E. G., Tenhaeff, W. E., Dudney, N. J. \& Pharr, G. M. Mechanical characterization of LiPON films using nanoindentation. Thin Solid Films $\mathbf{5 2 0}$, 413-418 (2011).

18. Kamaya, N. et al. A lithium superionic conductor. Nat. Mater. 10, 682 (2011)

19. Kato, Y. et al. High-power all-solid-state batteries using sulfide superionic conductors. Nat. Energy 1, 16030 (2016).

20. Fu, K. et al. Toward garnet electrolyte-based Li metal batteries: an ultrathin highly effective, artificial solid-state electrolyte/metallic Li interface. Sci. Adv. 3, e1601659 (2017).

21. Yue, J., Yan, M., Yin, Y.-X. \& Guo, Y.-G. Progress of the interface design in all-solid-state Li-S batteries. Adv. Funct. Mater. 28, 1707533 (2018).

22. Liu, Y. et al. Transforming from planar to three-dimensional lithium with flowable interphase for solid lithium metal batteries. Sci. Adv. 3, eaao0713 (2017).

23. Jung, Y. S., Oh, D. Y., Nam, Y. J. \& Park, K. H. Issues and challenges for bulktype all-solid-state rechargeable lithium batteries using sulfide solid electrolytes. Isr. J. Chem. 55, 472-485 (2015).

24. Bouchet, R. et al. Single-ion BAB triblock copolymers as highly efficient electrolytes for lithium-metal batteries. Nat. Mater. 12, 452 (2013).

25. Tao, X. et al. Solid-state lithium-sulfur batteries operated at $37^{\circ} \mathrm{C}$ with composites of nanostructured $\mathrm{Li}_{7} \mathrm{La}_{3} \mathrm{Zr}_{2} \mathrm{O}_{12}$ /carbon foam and polymer. Nano. Lett. 17, 2967-2972 (2017).

26. Xue, Z., He, D. \& Xie, X. Poly(ethylene oxide)-based electrolytes for lithium ion batteries. J. Mater. Chem. A 3, 19218-19253 (2015).

27. Zeng, X.-X. et al. Reshaping lithium plating/stripping behavior via bifunctional polymer electrolyte for room-temperature solid Li metal batteries. J. Am. Chem. Soc. 138, 15825-15828 (2016).

28. Long, L., Wang, S., Xiao, M. \& Meng, Y. Polymer electrolytes for lithium polymer batteries. J. Mater. Chem. A 4, 10038-10069 (2016).

29. Lin, Y., Wang, X., Liu, J. \& Miller, J. D. Natural halloysite nano-clay electrolyte for advanced all-solid-state lithium-sulfur batteries. Nano Energy 31, 478-485 (2017).

30. Lin, D. et al. Three-dimensional stable lithium metal anode with nanoscale lithium islands embedded in ionically conductive solid matrix. Proc. Natl Acad. Sci. USA 114, 4613 (2017).

31. Yang, C. et al. Continuous plating/stripping behavior of solid-state lithium metal anode in a 3D ion-conductive framework. Proc. Natl Acad. Sci. USA 115, 3770 (2018).

32. Fu, K. et al. Flexible, solid-state, ion-conducting membrane with $3 \mathrm{D}$ garnet nanofiber networks for lithium batteries. Proc. Natl Acad. Sci. USA 113, 7094 (2016).

33. Fu, K. et al. Three-dimensional bilayer garnet solid electrolyte based high energy density lithium metal-sulfur batteries. Energy Environ. Sci. 10, 1568-1575 (2017)

34. Liang, Z. et al. Composite lithium metal anode by melt infusion of lithium into a 3D conducting scaffold with lithiophilic coating. Proc. Natl Acad. Sci. USA 113, 2862 (2016)

35. Lin, D. et al. Layered reduced graphene oxide with nanoscale interlayer gaps as a stable host for lithium metal anodes. Nat. Nanotech. 11, 626 (2016).

36. Liu, N. et al. A pomegranate-inspired nanoscale design for large-volumechange lithium battery anodes. Nat. Nanotech. 9, 187 (2014).

37. Yao, H. et al. Crab shells as sustainable templates from nature for nanostructured battery electrodes. Nano. Lett. 13, 3385-3390 (2013).

38. Kovalenko, I. et al. A major constituent of brown algae for use in highcapacity Li-Ion batteries. Science 334, 75 (2011).

39. Chen, K. et al. Growing three-dimensional biomorphic graphene powders using naturally abundant diatomite templates towards high solution processability. Nat. Commun. 7, 13440 (2016).

40. Jeffryes, C., Campbell, J., Li, H., Jiao, J. \& Rorrer, G. The potential of diatom nanobiotechnology for applications in solar cells, batteries, and electroluminescent devices. Energy Environ. Sci. 4, 3930-3941 (2011).

41. Li, J. et al. Diatomite-templated synthesis of freestanding 3D graphdiyne for energy storage and catalysis application. Adv. Mater. 30, 1800548 (2018).

42. Ryu, J., Hong, D., Choi, S. \& Park, S. Synthesis of ultrathin Si nanosheets from natural clays for lithium-ion battery anodes. ACS Nano 10, 2843-2851 (2016).

43. Nassif, N. \& Livage, J. From diatoms to silica-based biohybrids. Chem. Soc. Rev. 40, 849-859 (2011). 
44. Luo, W. et al. Transition from superlithiophobicity to superlithiophilicity of garnet solid-state electrolyte. J. Am. Chem. Soc. 138, 12258-12262 (2016).

45. Wang, B. et al. Atomic layer deposited lithium silicates as solid-state electrolytes for all-solid-state batteries. ACS Appl. Mater. Interfaces $\mathbf{9}$, 31786-31793 (2017).

46. Lu, Y. \& Ni, Y. Effects of particle shape and concurrent plasticity on stress generation during lithiation in particulate Li-ion battery electrodes. Mech. Mater. 91, 372-381 (2015).

47. Chang, L., Lu, Y., He, L. \& Ni, Y. Phase field model for two-phase lithiation in an arbitrarily shaped elastoplastic electrode particle under galvanostatic and potentiostatic operations. Int. J. Solids Struct. 143, 73-83 (2018).

48. Wang, Z., Su, Q., Deng, H. \& Fu, Y. Composition dependence of lithium diffusion in lithium silicide: a density functional theory study. Chem. Electro Chem. 2, 1292-1297 (2015).

49. Arie, A. A. \& Lee, J. K. Estimation of Li-Ion diffusion coefficients in C60 coated Si thin film anodes using electrochemical techniques. Defect Diffus. Forum 326-328, 87-92 (2012).

50. Jung, S. C., Jung, D. S., Choi, J. W. \& Han, Y.-K. Atom-level understanding of the sodiation process in silicon anode material. J. Phys. Chem. Lett. 5, 1283-1288 (2014).

51. Wen, C. J. \& Huggins, R. A. Chemical diffusion in intermediate phases in the lithium-silicon system. J. Solid State Chem. 37, 271-278 (1981).

52. Ding, N. et al. Determination of the diffusion coefficient of lithium ions in nano-Si. Solid State Ion. 180, 222-225 (2009).

53. Chou, C.-Y. \& Hwang, G. S. Surface effects on the structure and lithium behavior in lithiated silicon: a first principles study. Surf. Sci. 612, 16-23 (2013).

54. Tang, W. et al. Lithium silicide surface enrichment: a solution to lithium metal battery. Adv. Mater. 30, 1801745 (2018).

\section{Acknowledgements}

We acknowledge the funding support from the National Natural Science Foundation of China (Grants 51571184, 21501165, 21431006, 51571184, and 21805268), the Foundation for Innovative Research Groups of the National Natural Science Foundation of China (Grants 21521001 and 11472262), the Users with Excellence and Scientific Research Grant of Hefei Science Center of CAS (2015HSC-UE007, 2015SRG-HSC038), Key Research Program of Frontier Sciences, CAS (Grant QYZDJ-SSW-SLH036), the Chinese Academy of Sciences (Grant KJZD-EW-M01-1), the Fundamental Research Funds for the Central Universities (Grant WK 2060190085), and the Strategic Priority Research Program of the Chinese Academy of Sciences (Grant No. XDB22040502). This work was partially carried out at the USTC Center for Micro and Nanoscale Research and Fabrication.

\section{Author contributions}

F.Z. and H.-B.Y. conceived the concept. H.-B.Y. and S.-H.Y. supervised the project. F.Z. Z.L. and B.S. carried out the synthesis and performed materials characterization and electrochemical measurements. Y.Y.L and Y.N. conducted the simulation of lithiation process and stress evolution. Y.G., X.-X.W. and B.-S.Z. assisted in the characterization of the electrode materials. Y.-C.Y. and L.-L.L. assisted in drawing figures and analyzing the electrochemical performance data. S.-H.Y. and Y.C. provided important experimental insights. F.Z., H.-B.Y. and S.-H.Y. cowrote the paper. All authors discussed the results and commented on the paper.

\section{Additional information}

Supplementary Information accompanies this paper at https://doi.org/10.1038/s41467019-10473-w.

Competing interests: The authors declare no competing interests.

Reprints and permission information is available online at http://npg.nature.com/ reprintsandpermissions/

Journal peer review information: Nature Communications thanks Kun Fu,Chih-Long Tsai and other anonymous reviewer(s) for their contribution to the peer review of this work. Peer reviewer reports are available.

Publisher's note: Springer Nature remains neutral with regard to jurisdictional claims in published maps and institutional affiliations.

(c) (i) Open Access This article is licensed under a Creative Commons Attribution 4.0 International License, which permits use, sharing, adaptation, distribution and reproduction in any medium or format, as long as you give appropriate credit to the original author(s) and the source, provide a link to the Creative Commons license, and indicate if changes were made. The images or other third party material in this article are included in the article's Creative Commons license, unless indicated otherwise in a credit line to the material. If material is not included in the article's Creative Commons license and your intended use is not permitted by statutory regulation or exceeds the permitted use, you will need to obtain permission directly from the copyright holder. To view a copy of this license, visit http://creativecommons.org/ licenses/by/4.0\%.

(C) The Author(s) 2019 